\title{
EDITORIAL
}

\section{REVISÃO INTEGRATIVA DE PESQUISA NA ENFERMAGEM O RIGOR CIENTIFICO QUE LHE É EXIGIDO}

\author{
Maria da Graça Oliveira CROSSETTI ${ }^{a}$
}

Iniciativas recentes e visíveis no desenvolvimento da pratica de enfermagem com base em evidencias, tem orientado a necessidade dos enfermeiros em consumirem e produzirem conhecimentos específicos inerentes a natureza do seu trabalho em diferentes contextos profissionais. Produções resultantes de procedimentos metodológicos diversos com destaque, no momento, para as revisões sistemáticas da literatura cujo fundamento teórico metodológico por si só, oferece conhecimentos profundo e abrangente em relação a um determinado fenômeno em estudo possibilitando ao enfermeiro decidir pela melhor conduta a ser tomada. Dentre estas abordagens pontua-se a Revisão Integrativa (RI) de pesquisa, que de modo crescente tem sido aplicada na produção científica na enfermagem em diferentes níveis tais como no desenvolvimento de trabalhos de conclusão de curso, monografias, dissertações e teses. Fato que se atesta com o crescente volume de artigos que aplicaram esta metodologia, submetidos e publicados em periódicos nacionais e internacionais. Não raro constata-se que o pesquisador menos experiente usa os termos revisão integrativa, revisão da literatura, revisão sistemática e meta-análise como sinônimos ${ }^{(1)}$. Embora haja algumas similaridades estas metodologias são diferentes, pois têm procedimentos distintos que levam ao alcance de objetivos e consequentes resultados igualmente distintos. A revisão da literatura se estrutura em resumos críticos de estudos sobre um tópico de interesse visando contextualizar o problema de pesquisa; se restringe a estudos relevantes que apontem para novos dados relacionados aos objetivos da pesquisa. Nesta revisão a atualização temporal das referências é o ponto crucial do rigor científico. A revisão sistemática se caracteriza por evidências de pesquisas cuidadosamente sintetizadas aplicadas para responder ás questões focadas na prática clinica; é conduzida exclusivamente a partir de rigoroso processo de seleção e análise de várias produções sobre o problema em estudo. A meta-análise é uma metodologia que quantitativamente integra e verifica a associação dos resultados de múltiplos estudos recentes, sobre um determinado evento da pratica clinica. A revisão integrativa sintetiza resultados de pesquisas anteriores, ou seja, já realizadas e mostra sobretudo as conclusões do corpus da literatura sobre um fenômeno específico, compreende pois todos os estudos relacionados a questão norteadora que orienta a busca desta literatura. Os dados resumidos e comparados permitem com que se obtenha conclusões gerais sobre o problema de pesquisa. Segue um processo de análise sistematico e sumarizado da literatura, o que se bem conduzido qualifica seus resultados o que possibilita identificar as lacunas do conhecimento em relação ao fenomeno em estudo, identificar a necessidade de futuros pesquisas, revelar questões centrais da área em foco, identificar marcos conceituais ou teóricos, mostrar o estado da arte da produção cientifica resultante de pesquisas sobre um determinado tema. Na condução da RI o pesquisasdor deve responder as seguintes questões ao avaliar o conhecimento já produzido, a saber: O que é conhecido? Qual é a qualidade do que é conhecido? O que deve ser conhecido? Qual é o próximo passo para a investigação ou prática ${ }^{(2)}$ ?

A revisão integrativa de literatura de pesquisa na enfermagem tem sido proposta por diferentes autores cujos procedimentos metodológicos se diferenciam no numero de etapas e na forma como propõem desenvolvê-las e apresentá-las. Contudo o processo segue básicamente cinco etapas: 1) formulação do problema, 2) coleta de dados ou definições obre a busca da literatura, 3) avaliação dos dados, 4) análise

a Professor Titular do departamento de Enfermagem Médico Cirúrgica da Escola de Enfermagem da UFRGS Coordenadora da Comissão Editorial da Revista Gaúcha de Enfermagem. 


\section{EDITORIAL}

dos dados e 5) apresentação e interpretação dos resultados ${ }^{(1,3,4,5)}$. A RI bem conduzida se caracteriza pela criticidade própria das pesquisas primárias no que se refere a replicação, clareza e rigor científico. Assim um dos aspectos fundamentais a ser considerado pelo pesquisador é o tamanho da amostra, ou seja, a busca da literatura deverá ser exaustiva. O que significa que poderá compreender a busca de artigos de pesquisa de há 20 a 30 anos ou mais atrás para encontrar as origens da prática em relação ao fenômeno em estudo. A relação dos artigos estará completa quando houver a saturação dos dados, o que se identifica a partir do momento em que ao verificá- la se constata que cada um doa artigos e os autores são familiares aos pesquisadores, ou a partir do momento em que se observa que os dados se caracterizam por um determinado padrão o que expressa a conclusão natural da revisão integrativa da literatura ${ }^{(2)}$.

O relatório final da RI para publicação não deve ser apresentado como uma série de sumarios ou resumos, mas contemplar a integração de conceitos, pensamentos, definições ou de outras informações relevantes própria dos autores cujas produções foram objetos de avaliação. O que significa que o foco do relatório será os resultados e consequentes conclusões oriundos da análise e discussão das informações extraidas dos artigos resutantes das pesquisas analisadas em resposta aos objetivos ou a questão norteadora do estudo.

RI da literatura, na pesquisa ao se fundamentar no rigor científico exigido para outras abordagens de pesquisa, representa mais um recurso para a construção do conhecimento em enfermagem e dado a sua natureza pode subsidiar o desenvolvimento e a acurácia da prática clínica e consequente intervenções que tenham como resultados a segurança do paciente.

\section{REFERÊNCIAS}

1 Cooper HM. The integrative research review: a systematic approach. Beverly Hills: Sage; 1984.

2 Russel CL. An overwiew of the integrative research review. Progress in Transplantion. Missouri: Columbia; 2005.

3 Whittemore R, Knafl K. The integrative review: updated methodology. J Adv Nurs. 2005;52(5):546-53.

4 Ganong LH. Integrative reviews of nursing research. Res Nurs Health. 1987;10(1):1-11.

5 Broome ME. Integrative literature reviews for the development of concepts. In: Rodgers BL, Knafl KA, organizador. Concept development in nursing: foundations, techniques and applications. Philadelphia: W.B. Saunders Company; 2000. p.231-50. 